\title{
Electronic communication in the construction industry
}

\author{
Marthinus J. Maritz \\ Department of Construction Economics, University of Pretoria, Pretoria, South Africa, and \\ Vaughan Hattingh \\ MDA Consulting (Pty) Ltd, Johannesburg, South Africa
}

\begin{abstract}
Purpose - The study aims to investigate how modern methods of communication within the construction industry have brought forth a new cognitive process that participants in this industry should undertake when communicating.
\end{abstract}

Design/methodology/approach - To achieve the objectives of the study, a literature review was compiled on the legal status of electronic communication and what the impact of the Electronic Communications and Transactions (ECT) Act, Act 25 of 2002, has had on electronic communication. A questionnaire was also distributed to quantity surveyors to ascertain the level of knowledge with regard to the application of the ECT Act.

Findings - The study found that participants are not familiar with the ECT Act and that it is highlyadvisable that parties to the agreement be made fully aware of how communications should be dealt with during the duration of the contract.

Research limitations/implications - The study is restricted to the South African construction industry and construction contracts and a small target population of professional quantity surveyors practicing in the Gauteng Province. The results of the research will be taken as representative of the entire country.

Practical implications - In the modern era, notifications are increasingly being communicated electronically, e.g. by electronic mail, linked computer networks, the Internet and cellular phones with appropriate media capabilities. Participants in the built environment must know how to correctly, effectively and legally, deal with this information revolution.

Originality/value - Modern means of communication, including in particular electronic emailing, demand that users properly appreciate whether the chosen method of communication has a contractually binding and legally enforceable effect. Thus, in an ever-changing built environment, participants should not only dedicate more time to ensure that information conveyed does not have legal implications, except if so intended, but that the information conveyed is unambiguous, grammatically correct and formulated professionally. This article has value as it investigates how industry stakeholders perceive the legal status of electronic communication and recommends how it should be dealt with during the execution of the contract.

Keywords

Built environment research, Contractual matters

\section{Introduction}

\subsection{Preamble and background}

The discussion in this article will be limited to the legal status and recent developments in electronic communication in the South African construction industry. The uninhibited evolution, ever increasing practical application of and 
extensive reliance upon modern methods of communication (including in particular electronic mailing) across the South African construction industry and elsewhere demands that users properly appreciate whether or not the chosen method of communication has a contractually binding and legally enforceable effect.

Only such an appreciation will effectively enable parties engaged in a particular construction activity to successfully implement either the contractually prescribed communication system or indeed any communication system at all throughout the duration of the construction activity.

The Electronic Communications and Transactions Act 2002 (hereafter referred to as the ECT Act) has largely clarified the legal status of modern methods of communication as employed. The enhancement has entrenched the protection afforded to parties under standard form construction contracts as to the acceptability (and consequent enforceability) of the contractually prescribed communication system, while simultaneously exposing parties to the legal consequences now entrenched by the ECT Act.

The built environment is a diverse environment with various role players and individuals from different professions including (among others) architects, engineers, sub-contractors, tradesmen, foremen, construction managers, and quantity surveyors who are consistently communicating with each other. Unambiguous communication between these parties, as well as a proper appreciation of the legal consequences of employing the various modern means of communication may carry, is therefore fundamentally important in enabling the successful implementation of either the contractually prescribed communication system or indeed any communication system at all.

Downey (2006: 160) cautions that: From conception to completion of a construction project, documents proliferate. Almost regardless of its completeness or accuracy, and however prone it may be to competing interpretations, a document provides a record. Moreover, when disputes arise, the purpose for which the record was originally created can be forgotten or ignored. The party who holds the best record therefore has the power of knowledge, and so it is not surprising that the prospects of a contractor recovering additional costs, or an employer resisting exaggerated claims, can increase almost in proportion to the quality of its paper trail. To that extent documents are needed. 


\subsection{Stating the problem}

With a rapidly changing communication landscape propelling towards a paperless environment, has the South African construction industry been able to effectively keep pace with these changes? Has electronic communication resulted in an uninhibited (often careless) flow of information or has the industry resisted this change? Do South African standard form construction contracts, such as the JBCC Series 2000 (JBCC) (published by the Joint Building Contracts Committee and currently in its sixth edition), make effective provision for use of electronic communications through execution of construction projects? How should electronic communications be recorded so as to be capable of being effectively presented as evidence in court? Can a simple email incorporating an embedded electronic signature satisfy specific contractual requirements for a "notice" under the contract or constitute a contractually compliant instruction to execute a variation or carrying out the instruction? While the ECT Act has clarified the legal status of modern means of communication, some confusion still prevails as to the application and extent of the ECT Act across the built environment.

A research report in partial fulfillment of the requirements for the honours degree in quantity surveying at the University of Pretoria that was submitted by P C Conradie in 2012 and supervised by one of the authors of this paper, Prof. Maritz, entitled Electronic communication, emailing and the legal status thereof within the construction industry, has been used as basis for this study. Additional content has been added by the authors of this paper to provide a more complete answer to the main problem stated hereunder.

The main problem that was stated in the abovementioned research report is that participants within the built environment are generally unfamiliar with the ECT Act and as a result doubtful of the actual legal consequences that employing the modern forms of communication has in either a contractually prescribed communication system or indeed any communication system at all. From the main problem two sub-problems were identified, which will be discussed in this paper by making use of the information contained in the research report and by adding additional content as described.

\subsection{Sub-problems}

1) How does the ECT Act affect the 'putting it in writing' and 'signature' rules, and 
how familiar are participants in the built environment with the ECT Act?

2) How does the ECT Act impact on the means of issuing a notification or variation in a contract?

\subsection{Hypotheses}

1) The legal status that an email and other forms of electronic communications uphold is generally not fully understood by participants in various sectors of the construction industry.

2) An electronic communication holds legal status to such an extent as to alter the original contract.

\subsection{Importance of the study}

Electronic communication is today an inevitable and intimate component of everyday business relations and contractually prescribed communication systems and indeed any communication systems. Due to the generally uncritical acceptance and application of the various modern means of communication across the South African construction industry over an extended period since their introduction, little thought is given by users as to the legal consequences that electronic communication may have that is consequent upon its application under the ECT Act. The study done is of significant importance in informing participants of these possible consequences.

Furthermore, when concluding a construction contract parties should carefully consider and expressly agree the means of acceptable project communications and contractually prescribe a communication system to be utilized for the duration of the construction activity. Clauses containing provision that "electronic means are deemed acceptable" are too general. It is progressively becoming critical to ensure that parties are able to maintain the "best record" of construction project documentation that specific forms of communications should now be dealt with expressly so as to ensure the promotion of legal certainty across the documentation exchanged between the parties and that a best record is available to stakeholders.

\subsection{Research methodology}

The primary data for the research report (supra) was gathered through the use of published and unpublished literature, as well as articles, the ECT Act and the 
Internet.

Secondary data for the research report (supra) was collected through a structured questionnaire. Participants consisted of quantity surveyors from different sectors, with varying years of experience.

The data were statistically analysed and processed for quantitative results. Results would ideally be used to determine any correlation between the relevant variables. The outcome of the study (findings and conclusions) could then be used in making recommendations and drawing conclusions.

\section{Interpretation of the ECT Act}

\subsection{Interpretation/Discussion}

Section (3) of the ECT Act, and the objectives and definitions of the ECT Act itself, explain to some extent the reasons for the Act coming into existence. The ECT Act however, should not be interpreted in isolation and does not exclude other relevant statutory law or common law principles.

\subsubsection{Objectives of the ECT Act}

"To provide for the facilitation and regulation of electronic communications and transactions; to provide for the development of a national e-strategy for the Republic; to promote universal access to electronic communications and transactions and the use of electronic transactions by SMMEs; to provide for human resource development in electronic transactions; to prevent abuse of information systems; to encourage the use of e-government services; and to provide for matters connected therewith."

Section 2(1) of the ECT Act, defines objects as to enable and facilitate electronic communications and transactions in the public interest, and for that purpose to:

a) recognise the importance of the information economy for the economic and social prosperity of the Republic;

b) promote universal access primarily in underserviced areas;

c) promote the understanding and, acceptance of and growth in the number of electronic transactions in the Republic; 
d) remove and prevent barriers to electronic communications and transactions in the Republic;

e) promote legal certainty and confidence in respect of electronic communications and transactions;

f) promote technology neutrality in the application of legislation to electronic communications and transactions;

g) promote e-government services and electronic communications and transactions with public and private bodies, institutions and citizens;

h) ensure that electronic transactions in the Republic conform to the highest international standards;

i) encourage investment and innovation in respect of electronic transactions in the Republic;

j) develop a safe, secure and effective environment for the consumer, business and the Government to conduct and use electronic transactions;

k) promote the development of electronic transactions services which are responsive to the needs of users and consumers;

I) ensure that, in relation to the provision of electronic transactions services, the special needs of particular communities and, areas and the disabled are duly taken into account;

m) ensure compliance with accepted International technical standards in the provision and development of electronic communications and transactions;

n) promote the stability of electronic transactions in the Republic;

o) promote the development of human resources in the electronic transactions environment;

p) promote SMMEs (Small, Medium and Micro Enterprises) within the electronic transactions environment;

q) ensure efficient use and management of the .za domain (the.za cc TLD 
assigned to the Republic according to the two-letter codes in the International Standard ISO 3166-I) name space; and

r) ensure that the national interest of the Republic is not compromised through the use of electronic communications.

\subsubsection{Sphere application}

Section (4) of the ECT Act - it is important for the application of the ECT Act in terms of construction that participants should note that the ECT Act will not override any requirements expressly agreed between contracting parties with regards to the manner in which a data message will be accepted by either person.

"Data message" for the purpose of the ECT Act is defined in Section 1 as meaning "data generated, sent, received or stored by electronic means and includes:

a) voice, where the voice is used in an automated transaction; and

b) a stored record."

Furthermore, the ECT Act does not override any law that specifically authorises, prohibits or regulates the use of data messages.

\subsubsection{Legal requirements for a data message}

Section 11 (1) of the ECT Act - clearly and unambiguously states that information captured partly or in whole in a data message (as defined), has legal force and should not be discharged on sole grounds that the information was captured in a data message. Note should however be taken that on proving a data message containing information, there are certain requirements that need to be met as to assure that the data message is legally enforceable.

Section 11 (2) of the ECT Act states that mere reference, for instance to an obligation clause in a contract, does have legal force although the information that is referred to did not represent itself in the data message. This interpretation of section 11(2) of the ECT Act is supported by Buys and Cronjé (2004: 85) stating that: It is a common occurrence that a single online communication is constituted by a number of different emails, each contributing elements to the whole 
'conversation', and each referring by context to information not contained in that specific data message. More commonly, data messages refer via hyperlinks to information hosted at remote web sites. In the online world, incorporation by reference could be said to be pivotal to pervasive use of all forms of electronic commerce. Buys and Cronjé (2004: 85), further emphasise a revolutionary consequence in South African jurisprudence by the ECT Act establishing legal certainty in information in the form of a data message, and further that information not included in a specific data message, but only referred to, does in fact now enjoy legal significance, provided the reference be by design or arise from ignorance.

Section 11 (3) of the ECT Act - enforceable amendment to a contract may be effected by data message. E-mailed correspondence satisfies both requirements. Van der Merwe, et al. (2008: 111) agree that amendments to existing agreements may now be concluded by a data message and evidenced by insertion of an advanced electronic signature embedded into the data message itself.

'Advanced electronic signature' is defined in section (1) of the ECT Act as "an electronic signature which results from a process which has been accredited by the Authority as provided for in section 3". Furthermore these amendments must have the characteristic that, should a reasonable person read through this amendment and without external explanations and data needed, it be clear that an amendment has been made and acknowledged by the other person. The format of the amendment is not prescribed, as long as it is reasonably capable of being reduced to electronic form by the party incorporating the amendment.

\subsubsection{Writing}

Further usefulness of a contract being reduced to writing is that the intent and nature of an agreement can be determined. By adding a signature to their agreement, parties acknowledge and accept that they are aware of the consequences of entering into an agreement. A written contract, undersigned by the parties, prevents repudiation to an extent and ensures compliance with legislation where a written record is required for validity (Buys and Cronjé, 2004: 85). Section (12) of the ECT Act provides that while a data message is construed as being in writing, the date message should be accessible in a manner that is usable for subsequent reference. Van der Merwe, et al. (2008: 111) emphasise the 
concept of written evidence, and point out that the document has to be accessible for future reference. Furthermore, van der Merwe, et al. (2008: 111) point out that it is not clear what steps the storage of a data message must take in order to ensure that it remains accessible for future reference and that some uncertainty exists before the ECT Act of whether a written term within a contract will be construed as being "written" if a document is stored electronically.

The communication system contractually prescribed under standard form construction contracts (including JBCC) typically require that certain classes of information be reduced to writing and thereafter exchanged between the parties. This requirements ensures (among other things) the existence of tangible evidence of exchanges between contracting parties during the construction project and creation of an auditable paper trail of project communications. Downey (2006: 161) observes that: The documents from a construction project are created for a number of purposes. At one end of the spectrum, they are issued to direct a contractor to do, or resist from doing something - such as instructions drawings and change orders. At the other end, they purport to record what is said to have happened or been discussed and agreed - such as minutes of meetings, site diaries and correspondence. In between, the contractual machinery generates a range of documents directed at keeping the other players informed, securing payment and/or confirming compliance with obligations - such as progress reports, programmes, commissioning data, applications for payment certificates, formal notices of claims, cost allocation sheets, etc.

\subsubsection{Signature}

The legal consequence, evidentiary value and, indeed, purpose of a signature and/or company logo embedded into emailed communication is unclear. Questions constantly arise regarding this formal requirement. For instance, does a scanned signature, copied and embedded into an email, hold sufficient legal force to support the conclusion that an email is undersigned?, or does an embedded company logo necessarily bind the particular company to the content of the data message?

In order to answer these and other similar questions, the definition/purpose of a signature, and whether or not an electronic signature complies with this definition/purpose thereof, should firstly be addressed. Buys and Cronjé (2004: 
86) have stated that a signature firstly has the purpose of being a mark or sign of a person that serves to ascribe certainty regarding respective rights and obligations, and secondly to identify the respective parties to a written agreement, and finally to verify that the parties involved have understood and expressly agreed to adhere to the terms and conditions recorded in the written document.

Buys and Cronjé (2004: 86) confirm that a paper-based signature may be verified through forensic investigation by handwriting experts. Electronic signatures generally do not refer to a scanned hand signature; as such the method of embedding a signature into emailed communication does not satisfy the requirements for qualifying as an advanced electronic signature prescribed under the ECT Act. Criteria for such a signature are specified by the Accreditation Authority, described under Section 37 of the ECT Act.

Section 13 (1) of the ECT Act, acknowledges that firstly a contract can incorporate specific requirements as to signature and may record agreement that the name of a person embedded into an email will suffice as evidence of such signature. This does however seldom happen, due to the inherent and obvious risks that exist with this method of signature. But, should no definition of what is regarded as a signature exists, the ECT Act provides that a data message undersigned with an advance electronic signature embedded into the communication is necessary for a data message is to be regarded as undersigned. 'Advanced electronic signature' is defined in section 1 to mean an electronic signature which results from a process which has been accredited by the Authority as provided for in Section 37.

Section 13 (2) of the ECT Act - subject to subsection (I), provides that an electronic signature is not without legal force and effect merely on the grounds that it is in electronic form.

Section 13 (3) of the ECT Act - when an electronic signature is required by the parties for an electronic transaction to commence and no agreement has been reached as to the method of this signature required. The requirement is satisfied if the method used is identified by the contracting parties have accepted this information. The second requirement that should be met is that the method by which the information was sent was as appropriate to the circumstances as possible and that the method used was not intended to cause ambiguity. 
Section 13 (4) of the ECT Act is clear and needs no further interpretation - "Where an advanced electronic signature has been used, such signature is regarded as being a valid electronic signature and to have been applied properly, unless the contrary is proved."

Section 13 (5) of the ECT Act - should no signature be required by either party a data message has legal effect. A "data message" may also be enforceable should there be a secondary verification that an intent to transact has been reached.

\subsubsection{Originality}

Section (14) of the ECT Act - if the law requires that information is to be presented in its original form, such requirement will be satisfied provided that the data message carrying the information has not altered the information from its origin to its final draft, except by normal course of communication, storage and display. Assessment of the integrity of the information must also be viewed in the light of the purpose for which the information was intended taking into account all circumstances that could have an influence with reference to the information.

Buys and Cronjé (2004: 89) pose the following question: What difference exists between a paper-based document which is replicated in digital format, and a document which is originated on a computer?

The difference is illuminated by the wording of Section 14 (1)(a) "... when it was first generated in its final form as a data message or otherwise ...". The ECT Act does not distinguish between these respective original states of documentation for the purposes of originality. The scanned version of a paper-based document no longer in existence will fulfil evidential requirements as an original as much as a document generated with word-processing software, provided that the provisions of Section 14 are complied with.

It should however be noted as stated by van der Merwe, et al. (2008: 116) that original paper documents have traditionally always carried more evidential weight than scanned, faxed or copied documents. The simple reason for this is that original paper documents may be verified through forensic testing. Aligning itself with this traditional approach the ECT Act requires that holders of important documents should keep the original documents for a certain period of time. 


\subsubsection{Admissibility and evidential weight of data messages}

Section 15 (1) of the ECT Act - no dismissal of evidence can be made when the only reason not to permit such evidence is that the nature of the evidence is a data message. Evidence can be provided that is not in its original form if the evidence is the best evidence that a person can provide.

Section 15 (2) of the ECT Act - data messages do carry due weight when presented, Section 15 (3) of the ECT Act - when data messages are presented assessment of the evidence will be made with regards to four factors:

- Assessment made of the reliability of the manner in which the data message was generated, stored or communicated.

- Whether the data messages' integrity was maintained.

- By which means the originator was identified.

- Any other relevant factor.

In order to comply with these relevant factors so as to ensure a data message is permitted as evidence, the participant attempting to permit such evidence should in addition refer to the Computer Evidence Act of 1983.

Section 15 (4) of the ECT Act - should a copy or printout of only a part of a data message be provided, the data message may be permitted as evidence, provided the message be certified as correct by an officer in the service of such a person.

\subsubsection{Variation by agreement between parties}

Section (21) of the ECT Act - note that Part 2 of the ECT Act (Sections 22 - 26) only applies to parties that have not reached an alternative agreement on the issues regulated in Sections $21-26$.

\subsubsection{Formation and validity of agreement}

Section 22 (2) of the ECT Act - an agreement was concluded at the time and place where an acceptance of an offer was received by the offeror.

2.1.10 Time and place of communications, dispatch and receipt

Section (23) of the ECT Act - a data message is regarded as being sent by the 
originator when it enters an information system outside the control of the originator, or should the addressee and originator be in the same information system, a data message is regarded as being sent when the data message is capable of being retrieved by the addressee.

A data message is regarded as being received when the data message enters an information system designated or used for that purpose by the addressee, and the data message is complete and is also able to be retrieved by the addressee.

A data message will be regarded as being sent as well as received by both the originator and addressees from their usual place of business or residence. Even if sent from another destination, for the purposes of considering where the agreement originated, the usual place of business or residence of the respective parties will be deemed to be contracting addresses.

\subsubsection{Expression of intent or other statement}

Section (24) of the ECT Act - this section concludes that should an expression of intent or other statement be made, it is not regarded as being without legal force merely on the ground that it is contained in a data message or that it does not hold an electronic signature.

\subsubsection{Attribution of data messages to originator}

Section (25) of the ECT Act - a data message is that of the originator, as if the originator has sent it himself. If a person had the authority to act on behalf of the originator with specific reference to the data message, or by an information system that was designed by the originator to act automatically, except if such system can be proven to be faulty.

\subsubsection{Acknowledgement of receipt of data message}

Section 26 (1) of the ECT Act - no acknowledgement is necessary so as to give legal effect to such a message.

\subsubsection{Accreditation of authentication products and services}

Section (37) of the ECT Act states that the Accreditation Authority may accredit products and service in support of what is defined as an electronic signature. An 
application for accreditation must be made to the Accreditation Authority in the prescribed manner supported by the prescribed information; and should be accompanied by a non-refundable prescribed fee. Should a company falsely sell their product stating that their product does comply with all the requirements of that of the ECT Act in terms of electronic signature, such a company will be found guilty of an offence.

Currently a product that is supplied by LAWtrust (Pty) Ltd. complies with the accreditation criteria of the ECT Act, in order to be recognised as an advanced electronic signature. (Claasen, 2012).

\subsection{Summary}

It is clear from the literature and consideration of the ECT Act that participants should make every endeavour to increase their awareness of the legal consequence that electronic means of communication carry while remaining acutely aware that data in its electronic form is not therefore regarded as being invalid.

Since the ECT Act entrenches the legal certainty and enforceability with regard to various forms of electronic communication the question necessarily follows as to whether or not participants across the construction industry should simply increase their awareness of the legal status and enforceability of electronic communication; or should construction contracts be more specific in dealing with the reality of electronic communications in implementation of a contractually prescribed communication system or indeed any communication system at all ?

FitzSimons (2013) recommends that the following procedures be implemented in managing electronic communications during implementation of construction projects, especially when dealing with the exchange of notices prescribed under each particular construction contract:

- email should be restricted to those notices that are unlikely to involve financial or other liability (although it may be difficult to ascertain what these will be and could ultimately create more problems);

- all email communication should be sent to and from one email address. This email address should be generic; and 
- if the contract does not specify email protocol or the parties have allowed email communication by their conduct, a deed should be entered into which outlines the protocol for the issuing of contractual notices by email. This deed may:

o outline the person all contractual notices should be sent to;

- require that all contractual notices sent by email include a statement that this email is a formal notice under the applicable clause of the contract;

- specify when an email notice is taken to be received (e.g. 24 hours after the email was sent, unless the party sending the email knows or ought reasonably to suspect that the email was not delivered to the addressee's domain specified in the email address); and

- include a requirement for a digital signature which can ensure authenticity.

\subsection{Testing of Hypothesis 1}

Hypothesis 1 in the research report (supra) assumed that participants within the construction industry are not fully informed of the extent of the application of the ECT Act, and the consequent legal status that email and other forms of electronic communications enjoy under the ECT Act.

In an attempt to prove the hypothesis formed, a questionnaire was sent to various participants within the construction industry, of which the majority studied quantity surveying or are actively involved within the construction industry as quantity surveyors.

Eighteen (18) questionnaires were completed and collected from a total of twenty four (24) sent. The received questionnaires were filed and data was captured in Microsoft Excel 2010. After capturing the data, data was exported to a pivot table in order to collect quantitative data for specific questions that would prove/disprove the hypothesis. The research design was non-experimental, the situation within the built environment, as it existed, was being investigated.

The following questions are quoted, followed by the results obtained in descending 
order of scale.

1) "How familiar are you with the ECT Act?" The following results were obtained:

$67 \%$ were 'Unfamiliar' with the ECT Act, $22 \%$ were 'Slightly familiar', $11 \%$ were 'Moderately familiar', $0 \%$ were 'Very familiar' and $0 \%$ were 'Extremely familiar' (Figure 1).

The results clearly proved the hypothesis that participants are not fully informed of the application of the ECT Act.

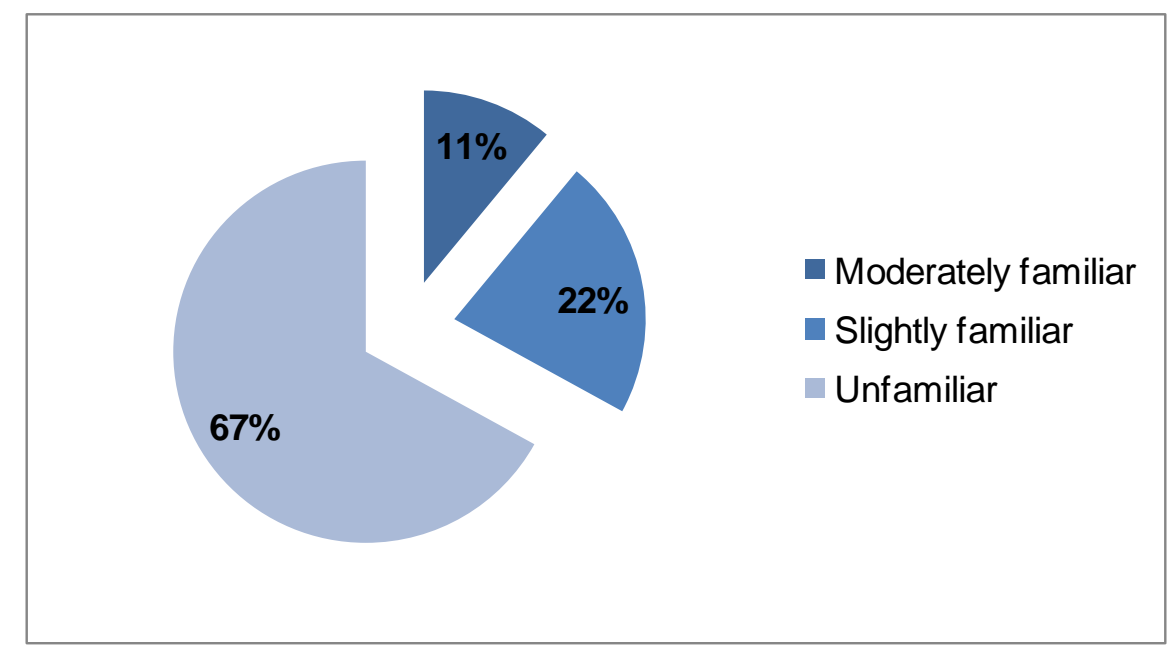

Figure 1 - How familiar are participants with the ECT Act?

2) "Does an email hold legal status?" The following results were obtained when this question was posed to participants. $\mathbf{8 9 \%}$ of participants acknowledged that an email does indeed hold legal status, whereas $11 \%$ believed emails do not have any legal status. The study indicated that although $67 \%$ of participants in the previous question regarding familiarity with the ECT Act were unaware of the ECT Act, common practice has lead towards the legal status that this form of communication upholds (Figure 2). 


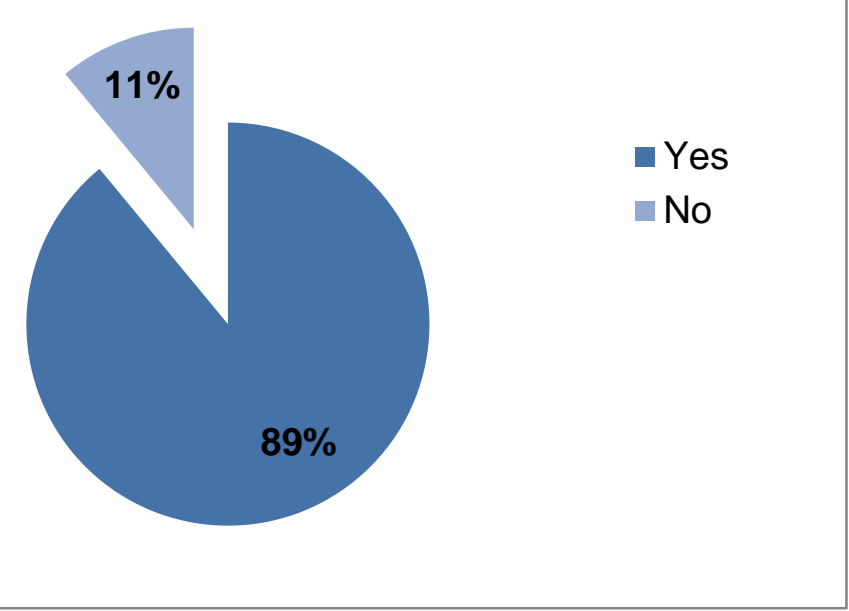

Figure 2 - Does an email hold legal status?

3) "When is an email legally deemed as received according to the ECT Act?" Participants were required to formulate in their own words at which point an email would be legally received by the recipient. $61 \%$ of participants were completely unable to answer this question. $17 \%$ of participants answered marginally correct and for the purpose of study, although not completely phrased as in the ECT Act, the principle involved has been sufficiently satisfied. Only $5 \%$ of participants took the JBCC's approach of being deemed received one (1) day after sent. The remaining $17 \%$ of participants incorrectly answered the question posed. (Figure 3).

Furthermore, due to the high percentage $(61 \%)$ of participants completely unable to answer the question posed, it would be a clear indication that emailing is, at this point in time, used as a source of communication, negotiation and information trading, but without the awareness of the inherent technicality that the legal status of this particular form of communication requires. 


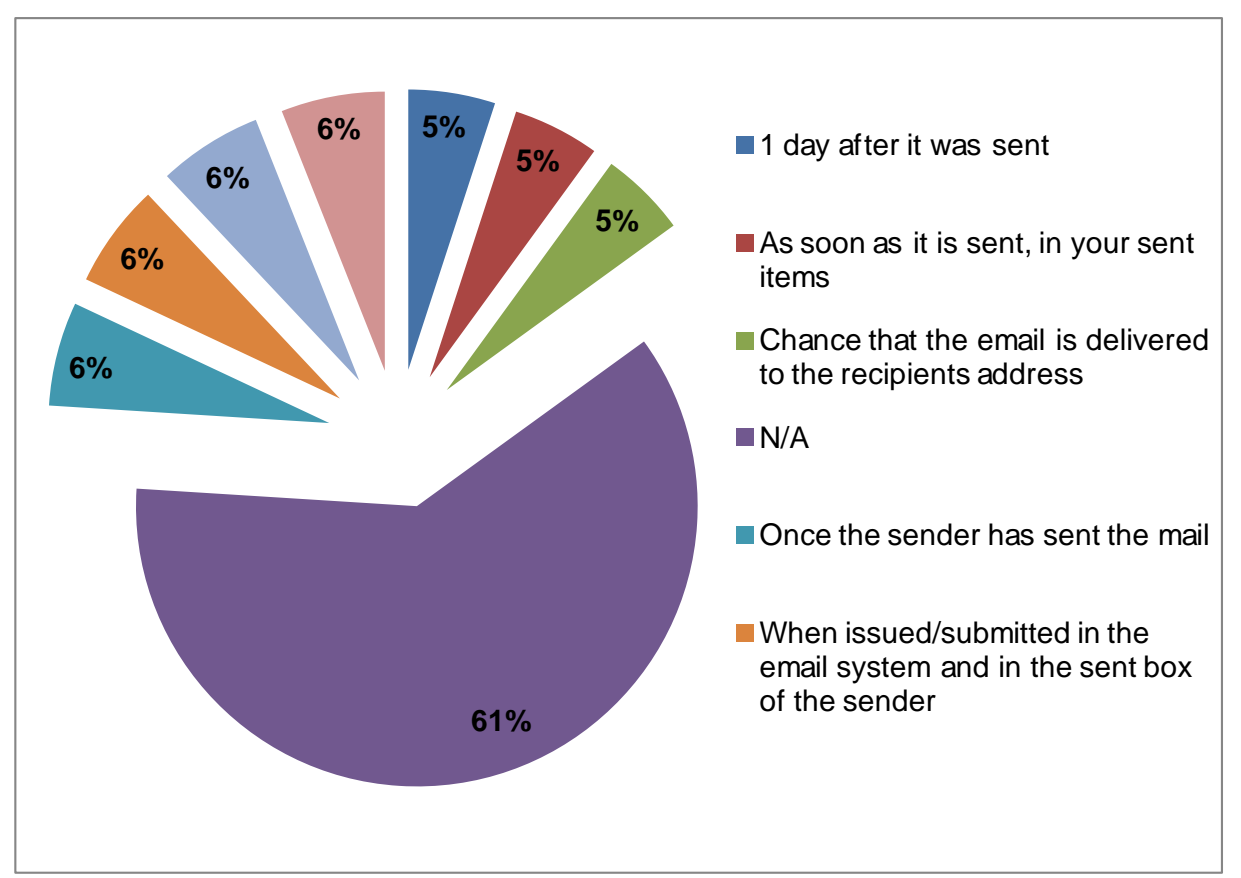

Figure 3 - When is an email legally deemed as received according to the ECT Act?

\section{Notices, contract instructions and relevant case studies}

\subsection{Introduction}

As previously discussed under the interpretation of the ECT Act, the question necessarily arises as to whether or not South African standard form construction contracts, in particular the JBCC, properly incorporate the provisions of the ECT Act into the express terms and, if so, how successful this incorporation has been.

This question may be addressed through a consideration of the mechanisms typically employed in the standard form construction contract to manage compliance with specific contractual requirements for issuing instructions and exchanging notices prescribed under each construction contract.

\subsection{Discussion/Interpretation}

\subsubsection{The 'in writing' rule}

Finsen (2005:114) has defined 'in writing' as “... includes drawings, faxes, e-mail, telegrams and magnetic tapes and computer discs in which words and drawings may have been electronically recorded and are capable of being converted to text and drawings on paper or other similar media." 
It is clear that Finsen in his definition of 'in writing' complied with the definition of 'data messages' of the ECT Act, which reads as follows:

'Data message' means data generated, sent, received or stored by electronic means and includes:
a) voice, where the voice is used in an automated transaction; and
b) a stored record.

\subsubsection{Instructions under and in terms of the construction contract}

Finsen (2005: 114) emphasises the importance in any contractually prescribed communication system for express provision that instructions (which among other things may vary the construction works) issued by the employer's representative only create a binding obligation upon the contractor to implement if and to the extent that such instruction is given in writing strictly in accordance with the provisions of the construction contract. The JBCC requires that to create a binding obligation to execute such an instruction shall only come into existence consequent upon “... a written instruction signed and issued by or under the authority of the principal agent to the contractor". The written instruction may be issued by the principal agent electronically i.e. in this instance by emailed communication (refer to subclause 2.5).

The ECT Act requires in relation to emailed communication that the word 'signed' be properly defined by parties, or in the absence of such specific definition, will have to satisfy the requirements for an 'advanced electronic signature' specified under Section 37 of the ECT Act to be regarded as having been signed by the relevant party - in this instance the principal agent issuing the written instruction.

Since no definition and/or provision of what the parties agree would constitute a signature for the purposes of emailed communications is provided under the JBCC, Section 13 (1) of the ECT Act necessarily applies. Section 13 (1) of the ECT Act provides that a signature embedded into an emailed communication shall, provided the requirements specified under section 13 (1) of the ECT Act are fulfilled, qualify as an advanced electronic signature and consequently the 
particular communication (in this instance an instruction) shall be treated as having been signed by the relevant party. Section 13 (1) of the ECT Act requires that to qualify as an advanced electronic signature; (a) the parties involved can be identified on the face of the emailed communication, and (b) the method of communication was appropriate to the circumstances.

The JBCC has retained the express requirement that a written instruction must be furnished by the principal agent to the contractor to create a legal obligation to execute the instruction (refer to sub-clause 17.5). The requirement that such instruction be signed by the principal agent in order for the instruction to create a contractual obligation to execute the specific instruction has been omitted.

The JBCC contains an advisory note suggesting that the principal agent should, when construction commences, discuss an appropriate procedure for requesting, issuing and recording contract instructions.

\subsubsection{Notices}

As a home grown South African standard form construction contract, developed through consultative processes among constituent representative groups under the auspice of the Joint Building Contracts Committee, the JBCC reflects current South African construction industry norms and practices with regard to (among other things) contractually prescribed systems for communication between the various stake holders during execution of the construction works.

Sub-clause 1.2.1 of the JBCC determines that when used through the contract the word "notice" and the words derivatives "indicate an act carried out in writing". Subclause 2.5.2 provides that "Notices shall be presumed to have been duly given when "Sent by electronic mail - within one (1) working day". Under the communication system prescribed through the JBCC a notice will only have contractual force and effect if the notice is specifically furnished "in writing".

Loots (1995: 580) has defined a notice as “... a formal written document required by the appropriate conditions of contract to advise the employer and/or his consultants of the circumstances giving rise to a claim". A notice further has the purpose of enabling the professional team or agents involved including the employer, to evaluate the specific event, consider possible negative 
consequences following the event and determine solutions to either avoid or mitigate the negative impact of the identified consequences.

The obligation on either party to a construction contract to furnish notice is necessarily specified through the express provisions of each particular construction contract. In specific instances the provisions requiring that notice be given typically also detail the consequence for failure to furnish the required notice either at all or within a specified period of time. Sub-clause 26.5 of JBCC, for example, accordingly requires that the contractor shall give notice to the principal agent within twenty (20) working days of becoming aware, or ought reasonably to have become aware of such expense and/or loss and concludes by specifying that failing which such claim shall be forfeited [our emphasis]. Consequent on the failure to furnish the required notification within the specified time period the contractor shall forfeit any and all entitlement to either extension of time and/or additional payment consequent on the event or circumstance.

In this instance furnishing the prescribed notice within the specified time period is a condition precedent to the contractor succeeding in a claim for additional compensation and/or extension to the time for completing the construction works. Such provisions are typically referred to in the construction industry as time bar clauses. Commenting on similar provisions contained under clause 20.1 of the FIDIC forms and clause 61.3 of the NEC 3 form Lal notes that the primary aim of each time bar clause is to 'alert' the employer/contract administrator to the contractor's claim, allow swift evaluation and to prevent the stockpiling of claims ${ }^{1}$.

The South African Appellate Division confirmed the general enforceability of these so called "time - barring" provisions in Alfred McAlpine \& Son (Pty) Ltd v Transvaal Provincial Administration 1974 (3) SA 506 (A). In Barkhuizen v Napier (CCT 72/05) the South African Constitutional Court echoed the Appellate Division approach in McAlpine \& Son (Pty) Ltd v Transvaal Provincial Administration.

In Hawkins \& Others v Enviroserve Waste Management [2009] 2 ZA SCA 162 (27 November 2008) the SCA was called on to consider whether notice as required

\footnotetext{
${ }^{1}$ Lal, Hamish, The rise and rise of time bar clauses for contractor's claims: issues for construction arbitrators, September 2007 at page 4, down loadable at www.scl.org.uk
} 
under clause 50.1 of the General Conditions of Contract for Works of Civil Engineering Construction $6^{\text {th }}$ edition (1990) (GCC 1990) entitling the contractor to claim compensation for additional work had been properly given by the contractor. The GCC 1990 is another home grown South African standard from construction contract developed and published by the South African Institution of Civil Engineering (SAICE).

In dismissing the appeal Mpati $\mathrm{J}$ (delivering a unanimous full bench judgment) at paragraph [14] quoted Jones $\mathrm{J}$ in the court a qou where Jines $\mathrm{J}$ said: The words 'give notice' in the law of contract frequently have a formal connotation, for example when used to terminate services, or to vacate premises. But not necessarily. The OED says that the words mean to intimate, to inform, to notify, to point out. In the context of clause 50 it seems to me that a legalistic definition is out of place. When the clause enjoins the contractor to give notice of adverse physical conditions, it requires him to advise or inform him about the adverse physical conditions. Simply put, he must tell him about them. He is not called to compose a formal legal document until he makes his claim in terms of section 51.

Mpati $\mathrm{J}$ went on to conclude at paragraph [17] that he can find no reason why a notice cannot be in the form of a letter, provided that the letter is so framed as to communicate unequivocally to the addressee that the writer is invoking, or relying upon, the provisions of the contract which provide for the giving of notice. It may do so expressly or by implication.

In the absence of provisions in the particular contract specifying when electronic mail shall be deemed received (as for example under sub-clause 1.2.1 read with subclause 2.5 of the JBCC which deems electronic mail received within one (1) working day) parties to construction contracts are advised to take particular note of Section 23 of the ECT Act. Section 23 of the ECT Act provides that:

"A data message is regarded as being received when the data message enters an information system designated or used for that purpose by the addressee, and the data message is complete and is also able to be retrieved by the addressee".

As mentioned above standard form construction contracts often provide that electronic communication (and other recognized more traditional communication forms) are "deemed to be received" after a specified period. Section 23 of the ECT 
Act however determines that an electronic communication will only be regarded as having been received once the data message enters the designated data system or data information system used specifically for that purpose. To avoid any conflict between these differing approaches it is highly recommended that provision be made in the construction contract obliging the receiving party to acknowledge receipt of the electronic communication by return of a read receipt (or similar mechanism) within a specified period.

Steyn $\mathrm{J}$ in CMC Woodworking Machinery (Pty) Ltd v Pieter Odendaal Kitchens, 2012 (5) SA 604 (KZD) observed at paragraph [2] that South Africa's legislature moved swiftly in recognising the evolution of communication systems. South Africa's new Companies $\mathrm{Act}^{2}$, which came into operation on 1 May 2011, paved the way for a change in the modus of giving notice. Section 6 (10) of the Act reads as follows: "If, in terms of this Act, a notice is required or permitted to be given or published to any person, it is sufficient if the notice is transmitted electronically directly to that person in a manner and form such that the notice can conveniently be printed by the recipient within a reasonable time and at a reasonable cost".

The move toward recognising the evolution of communication systems has similarly been recognised in South African High Court practice. As Steyn J states at paragraph [7] "On 27 July 2012 the Uniform Rules of Court were amended and Rule 4A was inserted after Rule $4^{3 "}$. The amendment incorporates some of the provisions of the Electronic Communications Act into the Rules and further states at paragraph [8] "Rule 4A specifically incorporates Chapter III, Part 2 of the Electronic Communications and Transactions Act, No 25 of 2002 as being applicable to effecting service by facsimile or electronic mail".

In granting an application to serve by substituted service only "a Notice of Set Down and pre-trial directions on the Defendant (a sole proprietorship) by sending the Notice via a Facebook message, in circumstances in which the Defendant's attorneys' withdrew and the Defendant consistently tried to evade service" [refer to paragraph [2]) Steyn $\mathrm{J}$ sounds a cautionary note in holding at paragraph [14] that "this application should be understood in the context in which it was launched and

\footnotetext{
${ }^{2}$ Act No. 71 of 2008.

${ }^{3}$ See Government Gazette No 35450, dated 22 June 2012
} 
the cogent reasons submitted on behalf of the applicant in support of the application. Each case will have to be decided on its own merits and on the type of document that needs to be served on the party concerned. This application has reminded me that even courts need to take cognisance of social media platforms, albeit to a limited extent, for understanding and considering applications such as the present".

INSERT J at paragraph [564] in Total South Africa (Pty) Ltd v Nedcor Bank Ltd (1997) 3 All SA 562 (W) observed that the obligation to give notice implies reciprocally that such notice must be received. In the absence of a deeming provision notice will not be deemed to have been given until such time as it is received.

Clause 2.5 of the JBCC incorporates such a deeming provision. Inclusion of a deeming provision affords the parties a mechanism to determine whether and when notice is in fact given. While undoubtedly contributing to creating an effective contractually prescribed communication system such deeming provisions do not provide an absolute solution. As pointed out by INSERT J (supra) at paragraph [14] in BMW Financial Services (SA) (Pty) Ltd v Harding and Another (2007) 4 All SA 716 (C) such deeming provisions creates a rebuttable presumption that the particular notice was in fact received by the recipient. The sender is relieved from the onus of proving that the recipient received the particular notice under the JBCC.

By contrast the FIDIC (1999 First Edition) standard form construction contracts do not contain such a deeming provision. Clause 1.3 paragraph (1) of the FIDIC Conditions of Contract for Construction provides that communications shall be in writing and delivered by hand (against receipt), sent by mail or courier, or transmitted using any agreed systems of electronic transmission as stated in the Appendix to Tender. The onus of proving receipt of the particular notice by the recipient rests squarely with the sender under the FIDIC (1999 First Edition) standard form construction contracts.

However, in the event that the particular notice is issued by electronic mail the provisions of section 23 of the ECT Act (unless agreed to the contrary by the parties) provide the parties with a test to determine exactly when the particular notice was received for the purposes of the contract - providing certainty between the parties as to what could become a hotly disputed point. By affording such 
certainty such legislative intervention undoubtedly contributes positively to the successful implementation of the contractually prescribed communication system or indeed any communication system.

\subsection{Summary}

The South African construction industry similarly needs to now seriously "start taking cognisance of social media platforms and other modern methods of communication including particular emailed communication in both day to day communications practices on construction projects and the specific provisions of construction contracts enabling the use of these modern forms of communications.

In doing so parties should become aware of and having done so actively employ technological solutions such as Microsoft Outlook's provision of request of 'Delivery and Read Receipts' albeit of limited application, third party email tracking solutions that use an invisible watermark in messages send that are recognise when the email (in which they are embedded) has been accessed and the system of 'Advanced Electronic Signatures' developed and accredited by LawTrust.

\subsection{Testing of Hypothesis 2}

Hypothesis 2 in the research report (supra) assumed that: "An email holds legal status to such an extent as to alter the original contract". No clear precedence exists directly supporting the hypothesis that emailed communication containing an embedded signature purporting to vary the terms of a written construction contract would be sufficient to constitute an amendment to a written construction contract.

Typically standard form construction contracts require that "No agreement or addendum varying, adding to, deleting or terminating this agreement including this clause shall be effective unless reduced to writing and signed by the parties" (refer statement under (unnumbered) Agreement at the end of JBCC's Principal Building Agreement). The two contractually stipulated requirements necessary to complete an amendment to the express terms of an existing written construction contract are that (a) the amendment be writing, and (b) that the amendment be signed by the parties. 
Section 12 of the ECT Act provides that "... a requirement in law that a document must be in writing, is met if the document is in the form of an email." Accordingly a contractual requirement that for an amendment to be effective the amendment must be in writing will similarly be satisfied if the amendment is contained in an emailed communication.

Whether not an embedded electronic signature in emailed communication would satisfy the second requirement requires consideration. Rhoodie (2012) in this regard observes that: "In terms of Section 13(1) of the ECT Act, the signature of a person is required by law and if laws do not specify the type of signature, the requirements in a data message are met if an advanced electronic signature is used. Section 13 (2), made subject to Section 13 (1), provides that an electronic signature is not without legal force and effect merely on the grounds that it is in electronic form. Section 13 (4) provides that where an advanced electronic signature has been used, such signature is regarded as being a valid electronic signature and to have been applied properly, unless the contrary is proved".

Accordingly an embedded electronic signature will by application of the aforementioned provisions of the ECT Act, unless the contrary is proven, satisfy the contractual requirement that the amendment be signed by the parties provided both parties append their respective electronic signatures to the amendment through the exchange of emailed communication.

In the research report (supra) respondents were asked to answer the following two questions on the legal status of emails:

1. What the legal strength of an email would be to give notice to parties in the contract?

In their response $5 \%$ of respondents indicated that an email has 'no legal status', $56 \%$ chose the option 'only if in good faith', and $39 \%$ acknowledged that an email would 'comply completely with all legal requirements' of a notice. From Figure 3.1, it is clear that the $95 \%$ of participants acknowledged that an email does have some legal status, although the larger portion felt that it would only be on good faith and not consequent upon the inherent legal status of the email itself (Figure 4). 


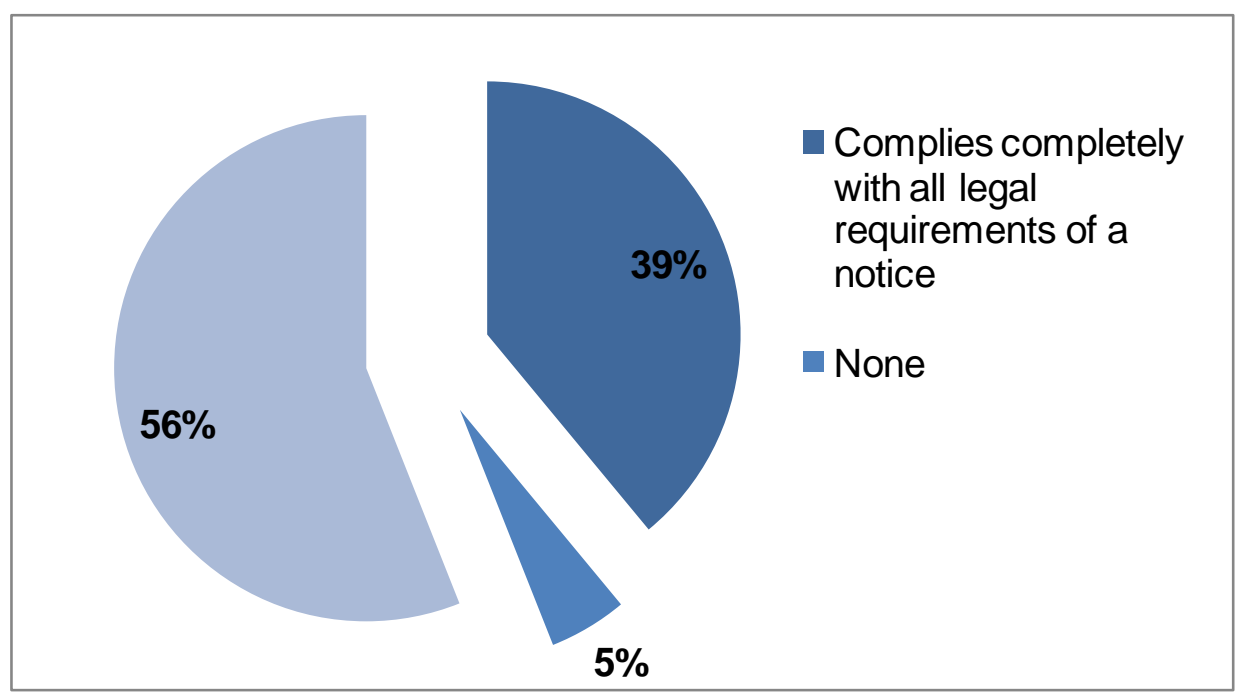

Figure 4 - What is the legal strength of an email to give notice to parties in a contract?

2. What the legal strength of an email would be if it was sent to another party in the contract, to bring a contract instruction into existence, if only via an email and not as an attached signed document?

In their response $44 \%$ of the respondents indicated that an email has 'no legal status' regarding variations, $39 \%$ chose the option 'only if in good faith' and $17 \%$ acknowledged that an email would 'comply completely with all legal requirements' so as to constitute a contractually binding instruction (Figure 5).

Responses confirmed that the majority of respondents thought an emailed communication alone could not vary the express terms of the construction contract and carried no more legal status than a notice. This response indicates that participants are, notwithstanding the evolution and consistent utilization of electronic communications, still fixated on the application of traditional systems of communication. In the traditional way of how variations are supposed to be issued. As argued above (see paragraph 3.4) and confirmed by Roodie's emailed communication does in fact hold sufficient legal status so as to constitute a binding variation to the express terms of a construction contract. 


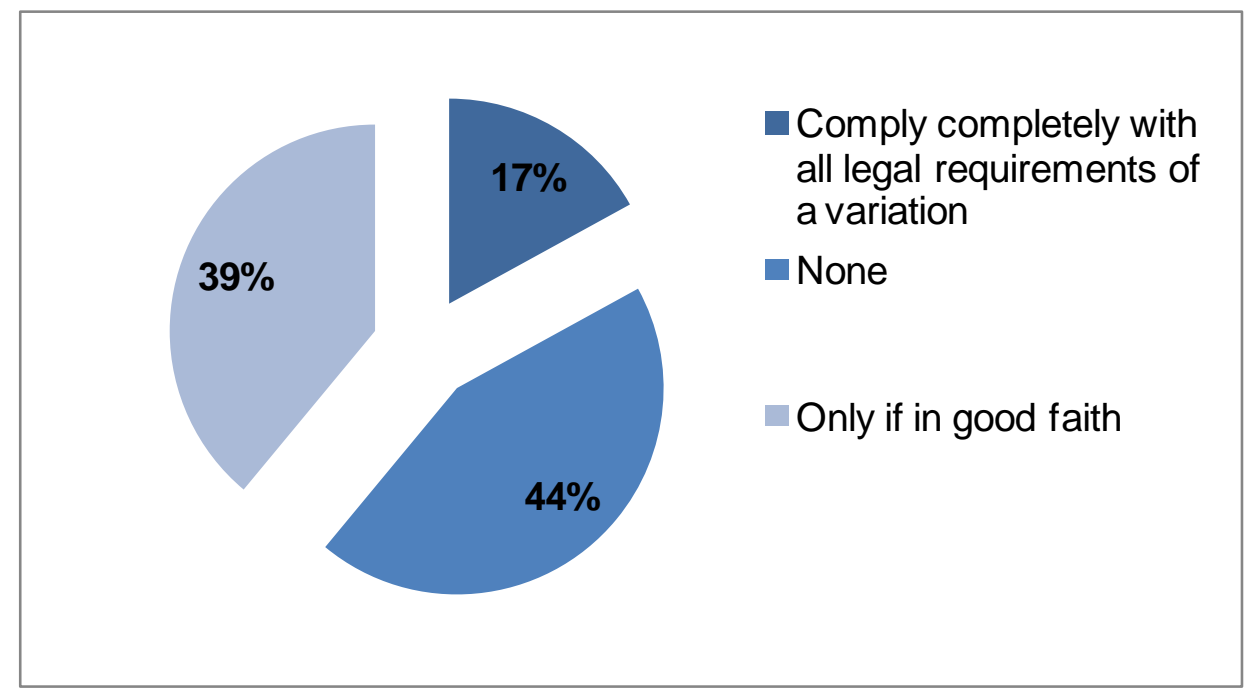

Figure 5 - What is the legal strength of an email to bring a contract variation into existence?

\section{Conclusion}

Standard form construction contracts typically rely on the exchange of notice(s) (usually prescribed to be in writing or now more commonly by electronically mailed communication - email) as the foundation for the communication systems prescribed through the contractual provisions. The contractually prescribed communication system(s) constructed around the simple exchange of notice(s) are geared to contribute to ensuring effective engagement between the various role-players throughout the duration of the construction activity.

Proficiently managing the contractual obligation to exchange notices during the construction activity is critically important to contributing toward the overall successfully implementation of the contractually prescribed communication system and (in certain contractually prescribed instances) vital in ensuring that entitlements to either extension of time and/or additional payment are brought to the parties' attention with sufficient clarity and certainty so as to be properly mitigated.

In agreeing a communication system to adhere to throughout the duration of a particular construction activity role players in the South African construction industry should particularly in regard to the unrestricted use of electronically mailed communication remain acutely aware of the fact that South African jurisprudence, while providing a degree of clarity and legal certainty as to the legal consequences for parties using this modern form of communication, continues to 
grapple with this evolving means for communicating.

Users should never lose sight of the absolute and continuing need to, in the face of the onslaught of evolving modern forms of communication, continue to strive to master the art of effective communications throughout the construction activity by fastidiously communicating, following up, confirming and requesting acknowledgement of receipt irrespective of the choice of modern form of communication.

\section{Source list}

Buys, R. \& Cronjé, F. 2004. Cyber law@SA2: The law of the internet in South Africa. $2^{\text {nd }}$ Ed. Pretoria: Van Schaik.

Claasen, L. 2012. Cyber signature services. Financial Mail, 12 June. [Online] Available from: http://www.fm.co.za/fm/2012/06/12/cyber-signature-service [Accessed: 2012-07/15]

Downey, R. 2006. What documents are really needed in order to resolve a construction dispute? Construction Law Journal, 2006, Vol. 22, No.3. United Kingdom.

Federation Internationale des Ingenieurs-Conseils (FIDIC). 1999. Conditions of Contract for Construction: For Building and Engineering Works Designed by the Employer. $1^{\text {st }}$ Ed. Lausanne: FIDIC.

Finsen, E. 2005. The Building contract: A commentary on the JBCC Agreements. $2^{\text {nd }} E d$. South Africa: Juta.

FitzSimons, J. 013. Did you know...sending contractual notices by e-mail can be dangerous? Available from: http://www.claytonutz.com/publications/newsletters/projects_insights/20070402/did_ you_know---_sending_contractual_notices_by_e-mail_can_be_dangerous.page [Accessed: 2013-01/07]

Joint Building Contracts Committee (JBCC). 2013. JBCC Series 2000 Principal Building Agreement. $6^{\text {th }}$ Ed (2013). Johannesburg: JBCC.

Longh, C.V. 2012. Article named: "Notices..." BKM published article, 
Johannesburg.

Loots, P.C. 1995. Construction Law and Related Issues. The Republic of South Africa: Rustica Press (Pty) Ltd.

McKenzie, H.S. McKenzie, S.D. \& Ramsden, P.A. 2009. McKenzie's Law of Building and Engineering Contracts and Arbitration. $6^{\text {th }}$ Ed. Cape Town: Juta.

Rhoodie, L. 2012. Email correspondence: enough to vary the terms of a contract. Johannesburg.

South Africa. 2002. Electronic Communications and Transactions Act. 2002.

Government Gazette, 466(23708):1-41.[Online] Available from: http://www.info.gov.za/view/DownloadFileAction?id=68060 [Downloaded: 2012/05/12]

South African Institution of Civil Engineering (SAICE). 1990. General Conditions of Contract for Works of Civil Engineering Construction, $6^{\text {th }}$ Ed. (1990). Johannesburg. SAICE.

The Writing Centre. 2012. Effective E-mail Communication. [Online] Available from: $\quad$ http://writingcenter.unc.edu/handouts/effective-e-mail-communication/ [Accessed: 2012-08-10]

Van der Merwe, D., Roos, A., Pistorius. \& Eiselen, S. 2008. Information and Communications Technology Law. Durban: LexisNexis. 